\title{
ANÁLISE SOCIODEMOGRÁFICA DAS HEPATITES VIRAIS NO ESTADO DO CEARÁ
}

SOCIODEMOGRAPHIC ANALYSIS OF VIRAL HEPATITIS IN THE STATE OF CEARÁ, BRAZIL

ANÁLISIS SOCIODEMOGRÁFICO DE LAS HEPATITIS VIRALES EN EL ESTADO DE CEARÁ, BRASIL

João Vitor Souza Marques

Beatriz Mendes Alves 2

Marcos Vinícius Souza Marques ${ }^{3}$

Cynara Carvalho Parente 4

Natanael Aguiar de Sousa ${ }^{5}$

Ticiana Mont'Alverne Parente Feijão 6

Palavras-chave:

Epidemiologia; Hepatite;

Promoção da Saúde; Vírus.

Keywords:

Epidemiology; Hepatitis; Health Promotion; Virus.

Palabras clave: Epidemiología; Hepatitis; Promoción de la Salud; Virus.

Submetido: $30 / 03 / 2019$

Aprovado: $21 / 09 / 2019$

Autor(a) para Correspondência: João Vitor Souza Marques Av. Dr. Guarani, 307, apto. 101 Derby Clube - Sobral (CE) 62042-030

E-mail: joao_vitorsm@hotmail. com

\section{RESUMO}

Este estudo teve por objetivo analisar o perfil sociodemográfico dos casos de hepatite viral (HV) no Estado do Ceará, no período entre 2010 e 2015. Trata-se de pesquisa documental, descritiva e retrospectiva, com abordagem quantitativa, realizada com informações colhidas no banco de dados do Sistema de Informação de Agravos de Notificação (SINAN) e examinadas por 2 pesquisadores independentes. Foram selecionadas 5 características epidemiológicas para avaliação: a) classificação etiológica; b) escolaridade; c) sexo; d) faixa etária; e e) raça. No período em foco, foram notificados 3.228 casos de HV. Ademais, notou-se oscilação no número de pacientes no decorrer desses anos. Constatou-se que homens, adultos, pardos e os vírus $B$ e $C$ foram as características mais relevantes. Vale salientar que não foi possivel traçar o perfil da doença em relação à escolaridade, uma vez que mais da metade dos casos foram ignorados ou não aplicados quanto a essa característica. Portanto, medidas voltadas à prevenção, ao diagnóstico precoce e ao tratamento eficaz, aliadas a maior qualidade das notificações, são ações importantes para reduzir o número de pacientes.

1. Aluno de Graduação em Medicina na Universidade Federal do Ceará (UFC). E-mail: joao_vitorsm@hotmail.com ORCID: https://orcid.org/0000-0003-1675-4416

2. Aluna de Graduação em Medicina na UFC. E-mail: beatriz_mendes.a@outlook.com ORCID: https://orcid. org/0000-0003-3739-7665

3. Aluno de Graduação em Medicina na UFC. E-mail: marcos_vinicius3600@hotmail.com ORCID: https://orcid. org/0000-0001-5642-2614

4. Bióloga. Doutora em Medicina Tropical pela Fundação 0swaldo Cruz (Fiocruz). Professora na UFC. E-mail: cynaraparente@hotmail.com ORCID: https://orcid.org/0000-0002-7927-0833

5. Aluno de Graduação em Medicina na UFC. E-mail: natan6521@gmail.com 0RCID: https://orcid.org/00000002-5162-1021

6. Farmacêutica. Mestre em Biotecnologia pela UFC. Professora na UFC. E-mail: ticianafeijao@uol.com.br ORCID: https://orcid.org/0000-0003-1266-4472 


\section{ABSTRACT}

This study aimed to analyze the sociodemographic profile of viral hepatitis (VH) cases in the State of Ceará, within the period from 2010 to 2015. This is a documentary, descriptive, and retrospective research, with a quantitative approach, conducted with information collected from the database of the Brazilian Information System for Notifiable Diseases (Sistema de Informação de Agravos de Notificação [SINAN]) and examined by 2 independent researchers. Five epidemiological features were selected for evaluation: a) etiological classification; b) schooling; c) sex; d) age group; and e) race. Within the period in focus, 3,228 VH cases were notified. Also, there was an oscillation in the number of patients over the years. Men, adults, browns, and viruses $B$ and $C$ were found to be the most relevant features. It is worth noticing that we did not manage to determine the disease profile in relation to schooling, since more than half of the cases were ignored or not applied regarding this feature. Therefore, measures aimed at prevention, early diagnosis, and effective treatment, combined to a better quality of notifications, are significant actions to reduce the number of patients.

\section{RESUMEN}

Este estudio tuvo como objetivo analizar el perfil sociodemográfico de los casos de hepatitis viral (HV) en el Estado de Ceará, en el período de 2010 a 2015. Se trata de una investigación documental, descriptiva y retrospectiva, con un enfoque cuantitativo, realizada con información recopilada de la base de datos del Sistema de Información de Enfermedades de Notificación de Brasil (Sistema de Informação de Agravos de Notificação [SINAN]) y examinada por 2 investigadores independientes. Se seleccionaron 5 características epidemiológicas para evaluación: a) clasificación etiológica; b) escolarización; c) sexo; d) franja etaria; y e) raza. Dentro del período en foco, se notificaron 3.228 casos de HV. Además, hubo una oscilación en el número de pacientes a lo largo de los años. Hombres, adultos, marrones y virus $B$ y C fueron las características más relevantes. Cabe señalar que no fue posible determinar el perfil de la enfermedad en relación con la escolaridad, ya que más de la mitad de los casos se ignoraron o no se aplicaron con respecto a esta característica. Por lo tanto, medidas dirigidas a la prevención, el diagnóstico precoz y el tratamiento efectivo, combinadas con una mejor calidad de las notificaciones, son acciones significativas para reducir el número de pacientes.

\section{INTRODUÇÃ O}

A hepatite é uma doença multifatorial que pode ser causada por vírus, drogas, álcool e alguns medicamentos, assim como doenças genéticas, autoimunes e metabólicas. Tais agentes causais levam à inflamação do fígado, caracterizando a doença propriamente dita. No Brasil, os tipos mais comuns responsáveis pela doença são os vírus $A, B$ e C. Na Região Norte existe o vírus $D$, que só causa infecção na presença do vírus tipo B. A hepatite E é relatada de modo esporádico no país ${ }^{1}$.

Em virtude da necessidade de mapear os casos de hepatite viral (HV) no Brasil, como forma de prover subsídios para a elaboração de diretrizes de políticas públicas, essa doença passou a ser de notificação compulsória, ou seja, os casos devem ser notificados por um profissional da saúde ${ }^{2}$.

0 modo de transmissão das HVs varia conforme o tipo do vírus. A hepatite A é transmitida pela via fecal-oral. Alimentos e água contaminados pelo vírus são os principais meios de veiculação dessa doença. Na hepatite $B$, a propagação da doença ocorre mediante soluções de continuidade (mucosas e pele), por vias parenterais, relações sexuais ou transfusões sanguíneas, além do uso de drogas endovenosas, entre outros modos. Já a ocorrência de hepatite $C$ se relaciona a contato direto, por via percutânea ou por meio de sangue contaminado ${ }^{3}$.

0 diagnóstico das HVs se baseia na detecção de marcadores encontrados no fluido oral, soro, plasma ou sangue da pessoa infectada, utilizando métodos de imunoensaio e/ou identificação do DNA viral pautados pela biologia molecular. A crescente evolução tecnológica no campo diagnóstico possibilitou o avanço das técnicas de imunoensaio cromatográfico utilizadas nos chamados testes rápidos (TRs), que são de fácil manipulação, não exigem infraestrutura laboratorial e proporcionam resultados em 30 minutos - fato que ampliou 0 acesso ao diagnóstico das $\mathrm{HVs}^{4}$.

Geralmente, as HVs não apresentam sinais e sintomas evidentes, contudo, quando estes estão presentes, vale destacar os quadros de cansaço, tontura, enjoo e/ou vômito, febre, dor abdominal, urina escura, olhos e pele amarelados e fezes claras. 0 tempo de surgimento dos sinais e sintomas varia de acordo com o tipo de vírus infectante e 
as características imunológicas dos hospedeiros. Normalmente, ocorrem durante um período entre 15 dias e 6 meses, mas a doença também pode tornarse crônica, fato relacionado, sobretudo, à hepatite C. Mostra-se importante ressaltar, ainda, que a cronificação da doença constitui fator de risco para o desenvolvimento de câncer de fígado ${ }^{5}$.

Não existe terapêutica específica na fase aguda da HV. Quando necessário, deve-se recorrer apenas ao tratamento sintomático de vômito, náusea e prurido. Além disso, sugere-se repouso ao paciente até que sejam normalizados os níveis de aminotransferase e o uso de álcool deve ser suspenso por um período mínimo de 6 meses. Na fase crônica, a realização de biópsia do fígado é fundamental para avaliar a necessidade de tratamento específico. As formas crônicas da doença têm diretrizes de tratamento definidas pelo Ministério da Saúde (MS). Em virtude da alta complexidade da terapêutica, do seguimento clínico e do manejo de efeitos colaterais, o tratamento deve ser realizado em serviços de média ou alta complexidade no âmbito do Sistema Único de Saúde (SUS) ${ }^{6}$.

Em 2015, no mundo, as HVs causaram 1,34 milhão de mortes - estatística comparável à tuberculose e ao vírus da imunodeficiência humana (human immunodeficiency virus [HIV]). Contudo, enquanto se nota redução da mortalidade em virtude de tuberculose e HIV, tem-se percebido aumento da mortalidade devido às HVs: cerca de 1,75 milhão de pessoas foram infectadas pela hepatite $\mathrm{C}$ e o número de pessoas com essa doença chegou a 71 milhões, mas, graças ao crescente aumento da cobertura vacinal contra as HVs entre as crianças, o número de novas infecções pela hepatite $B$ vem diminuindo ${ }^{7}$.

A análise epidemiológica das HVs no Brasil mostra que, a partir de um panorama histórico entre 2007 a 2017, houve mudança de seu perfil. Em 2007, a taxa de incidência de hepatite $A$ era superior às outras HVs ( $B, C$ e $D)$, contudo, após esse ano ocorreu uma importante queda desse agravo. Ainda nesse período, observou-se aumento nas taxas das hepatites $B$ e $C$ e a hepatite $C$ apresentou crescimento superior ao da hepatite $B$ a partir de 2015, ano em que ocorreu alteração da definição de casos (até 2014, a notificação de hepatite C ocorria somente com a presença de 2 marcadores - antiHCV e HCV RNA -, mas esse critério mudou em 2015, passando a demandar apenas 1 desses marcadores) com propósitos epidemiológicos. Já as menores taxas corresponderam à hepatite $D$, que se manteve

\section{As formas \\ crônicas da doença \\ têm diretrizes de \\ tratamento \\ definidas pelo \\ Ministério da Saúde.}

constante durante esse período ${ }^{8}$.

0 Ceará se encontra em $4^{\circ}$ lugar no ranking dos estados com menor incidência de hepatite no país $(0,29$ casos/100.000 habitantes). A hepatite $C$ apresenta o maior número de notificações nesse estado. Em 2017, a taxa de notificação desse vírus foi de 11,9/100.000 habitantes. Além disso, o Ceará também tem uma das menores taxas de morte em decorrência das HVs. Entre 2000 e 2016 ocorreram 749 óbitos em virtude das HVs ${ }^{9}$.

Apesar desses números ilustrarem um cenário melhor do que o de outros estados, o Ceará ainda apresenta muitos casos. Assim, avaliar o perfil epidemiológico dos pacientes viabiliza a elaboração de estratégias de saúde voltadas à intervenção para o diagnóstico precoce das HVs, possibilitando o aperfeiçoamento de métodos eficientes para 0 tratamento das pessoas infectadas.

Nesse contexto, o objetivo deste estudo foi:

- Analisar o perfil sociodemográfico dos casos de hepatite viral no Estado do Ceará, no período entre 2010 e 2015.

\section{METODOLOGIA}

Trata-se de pesquisa documental, descritiva e retrospectiva, com abordagem quantitativa, realizada em novembro e dezembro de 2018 com informações colhidas no Sistema de Informação de Agravos de Notificação (SINAN). Foram avaliados todos os casos de HV no Ceará de 2010 a 2015 - não havia estatísticas consolidadas para os anos de 2016 a 2018 na época da coleta de dados.

Para elaborar o perfil epidemiológico das HVs no estado, as variáveis colhidas foram: a) escolaridade; b) raça; c) sexo; d) faixa etária; e e) classificação etiológica da doença em cada pessoa. E este estudo não incluiu casos de não residentes no Brasil.

A coleta de informações foi realizada por 2 pesquisadores independentes e os dados foram processados no software Microsoft Excel, versão 2010, 
com variáveis organizadas por ano. Isso possibilitou a análise do perfil anual das infecções e sua evolução temporal, investigando o processo saúde-doença no Ceará. Além disso, recorreu-se a o software Microsoft Power Point, versão 2010, para a elaboração de gráficos ilustrativos das características mais relevantes a discutir neste artigo. Por fim, foram elaboradas tabelas para abordar as variáveis sociodemográficas das HVs.

Por utilizar o SINAN, uma plataforma do MS cujos dados estão disponiveis para livre acesso, este estudo não foi submetido à avaliação de um comitê de ética em pesquisa.

\section{RESULTADOS E DISCUSSÃO}

De acordo com as informações colhidas no SINAN, o Estado do Ceará apresentou um total de 3.228 casos de HV entre 2010 e 2015. Na Figura 1, observa-se uma oscilação do número de pacientes no decorrer desse período. Tal fato se assemelha a que ocorreu no Brasil entre 1999 e 2010, quando o país apresentou grande variação no número de casos de $\mathrm{HV}^{10}$.

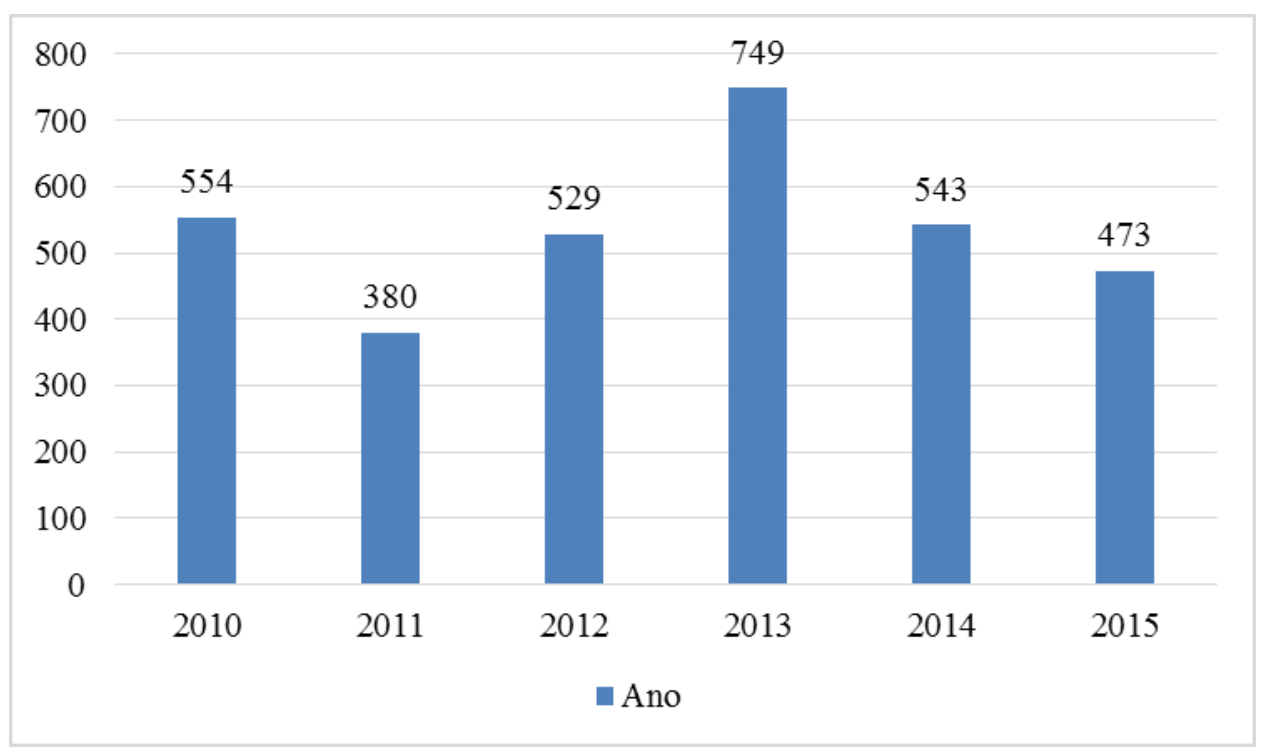

Figura 1. Número de casos de hepatite viral por ano. Sobral, 2018.

Fonte: Elaborada pelos autores.

Essa variação no número de casos de HV no Ceará pode estar associada à fragilidade das ações em vigilância sanitária voltadas à diminuição da incidência dessa doença. Combinadas a isso, medidas preventivas insuficientes voltadas a cada tipo de hepatite também podem ser a causa das oscilações no número de casos, como identificou um estudo realizado no Rio Grande do Sul, que avaliou os aspectos epidemiológicos e preventivos dessa doença no país e constatou que normas eficientes de vigilância em saúde e estudos sobre epidemiologia e prevenção constituem importantes fatores para a redução dos casos de HV3.

Ademais, tais oscilações no número de casos no período em foco parecem estar relacionadas às diferentes formas de diagnóstico dessa doença, causando heterogeneidade de notificações, como mostra um estudo realizado em São Paulo: parece haver maior homogeneidade de diagnóstico na sub-rede de sorologia, o que se reflete no aumento das notificações. Contudo, na sub-rede de biópsia de fígado ocorre atendimento insuficiente às demandas das HVs ${ }^{11}$.

A Tabela 1 mostra que 2.097 casos (mais de 64\%) tiveram classificação clínica relacionada ao vírus B ou C entre 2010 e 2015. Esses números chamam a atenção devido aos malefícios que esses tipos da doença podem causar aos seus portadors ${ }^{12}$. 
Tabela 1 - Casos de hepatite viral por classificação etiológica da doença. Sobral, 2018.

\begin{tabular}{lcc}
\hline Classificação clínica & $\mathrm{N}$ & $\%$ \\
\hline Ignorada/em branco & 128 & 3,96 \\
Vírus A & 973 & 30,15 \\
Vírus B & 903 & 27,98 \\
Vírus C & 1.151 & 35,65 \\
Vírus A+B & 10 & 0,32 \\
Vírus A+C & 3 & 0,09 \\
Vírus B+C & 43 & 1,33 \\
Vírus B+D & 6 & 0,18 \\
Não se aplica & 11 & 0,34 \\
\hline Total & 3.228 & 100 \\
\hline
\end{tabular}

Fonte: Elaborada pelos autores.

Dentre os agravos à saúde do portador de hepatite B ou C, vale destacar que essas doenças constituem algumas das principais etiologias relacionadas à gênese da cirrose. Além disso, esses vírus estão associados a carcinoma hepático ${ }^{12}$. Tendo em vista que a transmissão dos vírus $B$ e $C$ decorre de relações sexuais sem proteção, do uso de drogas injetáveis e de transfusões sanguíneas, por exemplo3, o elevado percentual de pessoas infectadas por esses tipos virais no Ceará pode gerar problemas de saúde pública. Contudo, a maior prevalência desses agentes não se restringe a esse estado, como se observa no Boletim Epidemiológico do MS, que afirma serem esses tipos virais os mais prevalentes na população brasileira8, fato que ressalta ainda mais a necessidade de ampliar os meios de prevenção dessa doença em todo o país.

$\mathrm{Na}$ Tabela 2 se observa que 1.763 casos $(54,6 \%)$ tiveram suas notificações ignoradas ou não aplicadas. Em segundo lugar com 744 notificações $(23,1 \%)$ se encontra o grupo de pessoas com Ensino Fundamental incompleto. 0 restante dos casos $(22,3 \%)$ corresponde às pessoas com no mínimo Ensino Fundamental incompleto. Diante disso, é perceptível que não se pode traçar um perfil adequado dos casos de HV no período em questão em termos de escolaridade, pois mais da metade dos casos foi negligenciada em termos de notificação adequada nesse período.
Tabela 2 - Casos de hepatite viral por escolaridade. Sobral, 2018.

\begin{tabular}{|c|c|c|}
\hline Escolaridade & $\mathrm{N}$ & $\%$ \\
\hline Ignorada/em branco & 1.426 & 44,2 \\
\hline Analfabeto & 53 & 1,7 \\
\hline $\begin{array}{l}\text { Ensino Fundamental } \\
\text { incompleto ( } \text { ão concluiu da } \\
1^{\text {a }} \text { à } 4^{\text {a }} \text { série) }\end{array}$ & 265 & 8,2 \\
\hline $\begin{array}{l}\text { Ensino Fundamental } \\
\text { incompleto (concluiu da } 1^{\text {a }} \\
\text { à } 4^{\text {a }} \text { série) }\end{array}$ & 106 & 3,3 \\
\hline $\begin{array}{l}\text { Ensino Fundamental } \\
\text { incompleto (não concluiu da } \\
5^{\text {a à } 8^{a} \text { série) }}\end{array}$ & 320 & 9,9 \\
\hline $\begin{array}{l}\text { Ensino Fundamental } \\
\text { completo }\end{array}$ & 133 & 4,1 \\
\hline Ensino Médio incompleto & 108 & 3,3 \\
\hline Ensino Médio completo & 328 & 10,2 \\
\hline Ensino Superior incompleto & 64 & 2 \\
\hline Ensino Superior completo & 88 & 2,7 \\
\hline Não se aplica & 337 & 10,4 \\
\hline Total & 3.228 & 100 \\
\hline
\end{tabular}

Fonte: Elaborada pelos autores.

Desse modo, ainda de acordo com os dados colhidos no SINAN, 1.203 notificações (84,3\%) ignoradas/em branco e/ou não se aplica ocorreram na macrorregião de saúde de Fortaleza. Isso merece destaque, considerando a possibilidade da existência de erros no processo de notificação dos casos da doença, como abordado em um estudo realizado na Bahia, que avaliou a qualidade das notificações de HV no Brasil entre 2007 e 2014 . Esse estudo diz que existem inconsistências em alguns dados notificados no SINAN e que houve crescimento dessas inconformidades no período em questão. Afirma-se, ainda, que um dos motivos para isso pode ser a quantidade de questões e páginas a preencher, o que contribui para o preenchimento inconsistente ou o não preenchimento ${ }^{13}$.

A Figura 2 ilustra que no Ceará, em todos os anos, o número de casos de HV foi maior no sexo masculino. Esse achado pode decorrer do fato dos homens apresentarem mais fatores de risco associados à transmissão de determinados tipos de vírus de hepatite: menor uso de preservativo, maior quantidade de parceiras(os) sexuais e maior uso e abuso de drogas ilícitas ${ }^{14-15}$. 


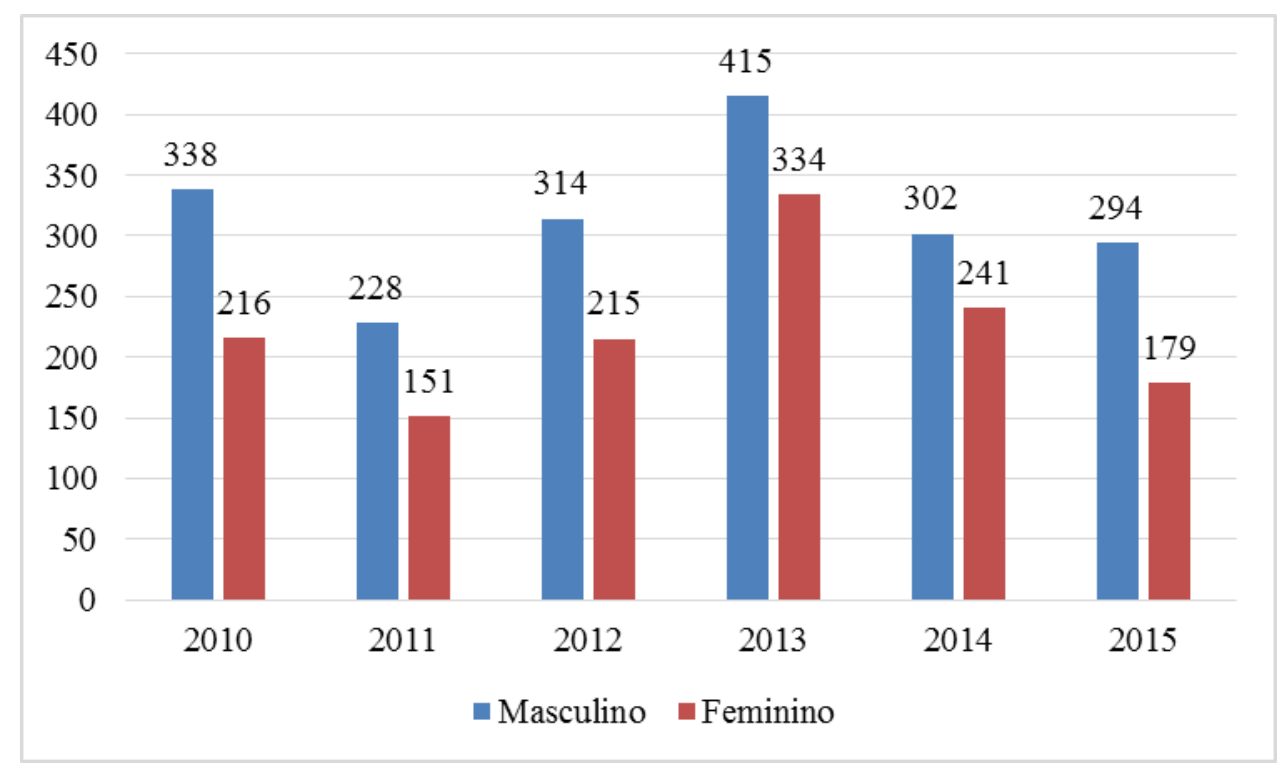

Figura 2. Número de casos de hepatite viral por sexo. Sobral, 2018.

Fonte: Elaborada pelos autores.

Outro estudo, realizado no Pará, encontrou dados semelhantes no que se refere à maior prevalência sorológica de homens. Nesse estado, 62,6\% dos casos notificados envolveram pessoas do sexo masculino. A pesquisa afirma que isso pode decorrer do comportamento sexual ${ }^{16}$.

A Tabela 3 mostra que entre 2010 e 2015 foram notificados 503 casos (15,6\%) em crianças de 0 a 9 anos, 380 casos $(11,8 \%)$ em jovens de 10 a 19 anos, 840 casos $(26,05 \%)$ em adultos de 20 a 39 anos, 1.042 casos $(32,3 \%)$ em adultos de 40 a 59 anos e 459 casos $(14,25 \%)$ em idosos com 60 anos ou mais. A partir desses dados, identifica-se que a maior quantidade de notificações da doença ocorreu em adultos (de 40 a 59 anos) nesse período.

Tabela 3 - Faixa etária dos casos de hepatite viral. Sobral, 2018.

\begin{tabular}{lccccccc}
\hline \multicolumn{7}{c}{ Faixa etária (anos) } \\
\hline Ano & Ignorado & $0-9$ & $10-19$ & $20-39$ & $40-59$ & $>60$ & Total \\
\hline 2010 & 1 & 122 & 87 & 156 & 125 & 63 & 554 \\
2011 & - & 63 & 52 & 102 & 119 & 44 & 380 \\
2012 & - & 121 & 62 & 132 & 158 & 56 & 529 \\
2013 & 1 & 124 & 92 & 180 & 238 & 114 & 749 \\
2014 & 2 & 56 & 65 & 146 & 196 & 78 & 543 \\
2015 & - & 17 & 22 & 124 & 206 & 104 & 473 \\
\hline Total & 4 & 503 & 380 & 840 & 1.042 & 459 & 3.228 \\
\hline
\end{tabular}

Fonte: Elaborada pelos autores.

Nesse contexto, resultados semelhantes foram encontrados em um estudo realizado no Município de Juruti (PA), publicado em 2010, no qual o maior número de casos de HV ocorreu entre adultos. Nesse município, foram sugeridas algumas medidas para reduzir o número de casos da doença, como: atividades de educação em saúde, destacando os cuidados na utilização de materiais contaminados (como escovas de dente, tesouras, barbeadores e preservativos) e na atenção às normas de segurança no trabalho. Além disso, sugere-se ampla cobertura vacinal, como forma de prevenir a contaminação pelo vírus $\mathrm{B}^{17}$. Tais medidas também podem ser adotadas no Ceará, uma vez que as características epidemiológicas relacionadas à faixa etária foram semelhantes.

$\mathrm{Na}$ Tabela 4, é notório que a maioria dos casos de HV nesse período ocorreu entre pardos (2.260 casos $70 \%$ ); esse número pode ser ainda maior quando se considera que 437 casos $(13,5 \%)$ foram ignorados quanto ao preenchimento do quesito (raça) no formulário de notificação. 0 segundo maior grupo com agravo nesse período foi o dos brancos (327 casos - 10,1\%). Merecem atenção, ainda, as pessoas pretas e amarelas (101 e 88 
casos $-3,1 \%$ e $2,8 \%$, respectivamente). Por fim, a população indígena apresenta 15 casos $(0,5 \%)$. Nesse contexto, atenta-se ao grupo composto por pardos, amarelos, pretos e indígenas, que, historicamente, apresentam vulnerabilidades sociais - somados, eles representam mais de $76 \%$ das notificações (2.464 casos).

Tabela 4 - Casos de hepatite viral por raça. Sobral, 2018.

\begin{tabular}{lcc}
\hline Raça & $\mathrm{N}$ & $\%$ \\
\hline Ignorada/em branco & 437 & 13,5 \\
Branca & 327 & 10,1 \\
Preta & 101 & 3,1 \\
Amarela & 88 & 2,8 \\
Parda & 2.260 & 70 \\
Indígena & 15 & 0,5 \\
\hline Total & 3.228 & 100 \\
\hline
\end{tabular}

Fonte: Elaborada pelos autores.

Um fator que pode estar relacionado ao elevado número de pardos entre os pacientes no Ceará diz respeito à própria característica da população: a Pesquisa Nacional por Amostra de Domicílios (PNAD) relativa a 2012 informa que a população cearense é composta por $63,96 \%$ de pessoas autodeclaradas pardas $^{18}$.

Contudo, essa estatística não é capaz de explicar, de modo isolado, porque o maior número de casos envolve pardos, uma vez que $70 \%$ das notificações ocorreram nessa população (Tabela 4).

Outro aspecto que pode explicar essa distribuição das HVs por raça diz respeito às desigualdades raciais; tal fator pode ser a causa do maior risco de adoecimento entre populações discriminadas em virtude das vulnerabilidades sociais e econômicas, ainda persistentes, enfrentadas por esses grupos. Pode-se confirmar tal argumento ao observar um estudo de amplitude nacional publicado no Rio de Janeiro, em 2005, que aponta as desigualdades raciais e sua influência no processo saúde-doença ${ }^{19}$.

Além disso, como observa um estudo publicado em 2008 em Sobral (CE), uma das chaves para o enfrentamento das desigualdades sociais se encontra na vigilância em saúde, que deve contar com participação ativa dos profissionais da saúde e da população geral, como forma de aprimorar a promoção da saúde e a recuperação do indivíduo e da comunidade ${ }^{20}$.

\section{CONCLUSÃO}

0 s resultados deste estudo mostram uma oscilação no número de casos no período enfocado. Constatouse que as infecções mais prevalentes envolvem os vírus $B$ e $C$, na população adulta, com prevalência do sexo masculino e da raça parda. Ademais, não foi possível traçar um perfil da doença relacionado aos níveis escolares, visto que ocorreram muitos casos ignorados e/ou não aplicados.

Nesse contexto, conclui-se que são necessárias medidas mais eficazes de prevenção, diagnóstico precoce e tratamento eficiente das HVs. Sugere-se, ainda, que deve haver maior controle e fiscalização das notificações, sobretudo na macrorregião de Fortaleza, com vistas a reduzir os casos dessa doença no Ceará, garantindo melhor qualidade de vida à sua população.

\section{CONTRIBUIÇÃO DOS AUTORES}

João Vitor Souza Marques contribuiu com a realização da pesquisa, o delineamento do estudo e a redação do manuscrito. Beatriz Mendes Alves e Marcos Vinícius Souza Marques contribuíram com a realização da pesquisa. Cynara Carvalho Parente contribuiu com a redação do manuscrito. Natanael Aguiar de Sousa e Ticiana Mont'Alverne Parente Feijão contribuíram com a revisão crítica do manuscrito.

\section{REFERÊNCIAS}

1. Ministério da Saúde. Hepatite: causas, sintomas, diagnóstico, prevenção e tratamento [document on the internet]. 2018 [cited 2018 Dec 12]. Available from: http://portalms.saude.gov.br/saude-de-a-z/ hepatite

2. Sistema de Informação de Agravos de Notificação. Hepatites virais [document on the internet]. 2016 [cited 2018 Dec 12]. Available from: http:// portalsinan.saude.gov.br/hepatites-virais

3. Ferreira CT, Silveira TR. Hepatites virais: aspectos da epidemiologia e da prevenção. Rev Bras Epidemiol [serial on the internet]. 2004 [cited 2018 Dec 13];7(4):473-87. Available from: http://www. scielo.br/pdf/rbepid/v7n4/10.pdf

4. Ministério da Saúde. Manual técnico para o diagnóstico das hepatites virais [document on the internet]. 2015 [cited 2018 Dec 13]. Available from: https://cevs.rs.gov.br/upload/ arquivos/201701/04162030-manual-diagnosticodas-hepatites-virais-ms-2015.pdf 
5. Universidade Aberta do SUS. Você sabe diferenciar as hepatites $A, B, C, D$ e E? [document on the internet]. 2014 [cited 2018 Dec 13]. Available from: https://www.unasus.gov.br/noticia/vocesabe-diferenciar-hepatites-b-c-d-e-e

6. Secretaria de Vigilância em Saúde. Hepatites virais [serial on the internet]. 2007 [cited 2018 Dec 14]. Available from: http://bvsms.saude.gov.br/bvs/ publicacoes/07 0044 M2.pdf

7. Organização Pan-Americana da Saúde. Novos dados sobre hepatites destacam necessidade de uma resposta global urgente [document on the internet]. 2017 [cited 2018 Dec 14]. Available from: https:// www.paho.org/bra/index.php? option $=$ com cont ent \&view $=$ article \&id $=5404$ :novos-dados-sobrehepatites-destacam-necessidade-de-uma-respostaglobal-urgente \&Itemid $=812$

8. Ministério da Saúde. Boletim epidemiológico: hepatites virais 2018 [document on the internet]. 2018 [cited 2018 Dec 14];49(31):1-72. Available from: http://portalarquivos2.saude.gov.br/images/ pdf/2018/julho/05/Boletim-Hepatites-2018.pdf

9. G1 - 0 Portal de Notícias da Globo. Ceará ocupa a $4^{\circ}$ posição entre os estados com menores incidências de hepatites do país [document on the internet]. 2018 [cited $2018 \mathrm{Dec} 14$ ]. Available from: https://g1.globo.com/ce/ceara/noticia/cearaocupa-a-4-posicao-entre-os-estados-com-menoresincidencias-de-hepatites-do-pais.ghtml

10. Ministério da Saúde. Boletim epidemiológico: hepatites virais 2011 [document on the internet]. 2018 [cited 2018 Dec 19];2(1):1-82. Available from: http://bvsms.saude.gov.br/bvs/periodicos/boletim hepatites 2011.pdf

11. Marques CCA, Carvalheiro JR. Avaliação da rede de diagnóstico laboratorial na implantação do Programa de Prevenção e Controle das Hepatites Virais no Estado de São Paulo, 1997-2012. Epidemiol Serv Saúde [serial on the internet]. 2017 [cited 2018 Dec 22];26(3):513-24. Available from: http://www.scielo.br/pdf/ress/v26n3/2237-9622ress-26-03-00513.pdf

12. Carvalho JR, Portugal FB, Flor LS, Campos MR, Schramm JMA. Método para estimação de prevalência de hepatites B e C crônicas e cirrose hepática Brasil, 2008. Epidemiol Serv Saúde [serial on the internet]. 2014 [cited 2018 Dec 23];23(4):691700. Available from: https://www.scielosp.org/pdf/ ress/2014.v23n4/691-700/pt

13. Cordeiro TMSC, D'0liveira Júnior A. Qualidade dos dados das notificações de hepatites virais por acidentes de trabalho, Brasil. Rev Bras Epidemiol [serial on the internet]. 2018 [cited 2018 Dec 23];(21):1-11. Available from: http://www.scielo.br/ pdf/rbepid/v21/1980-5497-rbepid-21-e180006.pdf
14. Dias JA, Cerutti Júnior C, Falqueto A. Fatores associados à infecção pelo vírus da hepatite $B$ : um estudo caso-controle no município de São Mateus, Espírito Santo. Epidemiol Serv Saúde [serial on the internet]. 2014 [cited 2018 Dec 22];23(4):683-90. Available from: https://scielosp.org/pdf/ress/2014. v23n4/683-690/pt

15. Barbosa RM, Koyama MAH, Grupo de Estudos em População, Sexualidade e Aids. Comportamento e práticas sexuais de homens e mulheres, Brasil 1998 e 2005. Rev Saúde Pública [serial on the internet]. 2008 [cited 2018 Dec 22];42(Suppl 1):2133. Available from: http://www.scielo.br/pdf/rsp/ v42s1/05.pdf

16. Aquino JA, Pegado KA, Barros LP, Machado LFA. Soroprevalência de infecções por vírus da hepatite $B$ e vírus da hepatite $C$ em indivíduos do Estado do Pará. Rev Soc Bras Med Trop [serial on the internet]. 2008 [cited 2018 Dec 23];41(4):334-7. Available from: http://www.scielo.br/pdf/rsbmt/v41n4/ a03v41n4.pdf

17. Nunes HM, Soares MCP, Brito EMF, Alves MM, Souza OSC, Borges AM, et al. Prevalência de infecção pelos vírus das hepatites A, B, C e D na demanda de um hospital no Município de Juruti, oeste do Estado do Pará, Brasil. Revista Pan-Amazônica de Saúde [serial on the internet]. 2010 [cited 2018 Dec 23];1(2):10511. Available from: http://scielo.iec.gov.br/pdf/ rpas/v1n2/v1n2a13.pdf

18. 0 Povo. PNAD: População no Ceará tem 63,96\% de pardos [document on the internet]. 2013 [cited 2018 Dec 23]. Available from: https:// www20.opovo.com.br/app/fortaleza/2013/09/27/ noticiafortaleza, $3137203 /$ pnad-populacao-noceara-e-de-63-96-de-pardos.shtml

19. Chor D, Lima CRA. Aspectos epidemiológicos das desigualdades raciais em saúde no Brasil. Cad Saúde Pública [serial on the internet]. 2005 [cited 2018 Dec 23];21(5):1586-94. Available from: http://www. scielo.br/pdf/csp/v21n5/33.pdf

20. Soares CHA, Linhares MSC. Vigilância à saúde no Município de Sobral-CE: aspectos históricos, conceituais e atuação na saúde pública. Sanare (Sobral, 0nline) [serial on the internet]. 2008 [cited 2019 Nov 18];7(1):6-11. Available from: https:// sanare.emnuvens.com.br/sanare/article/view/48/43
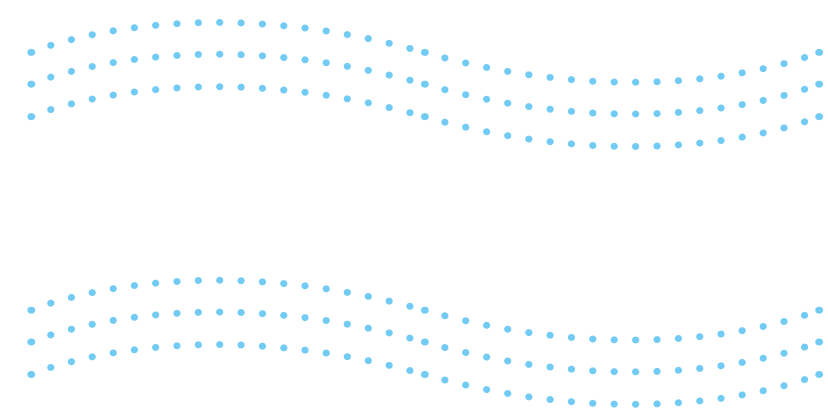

SANARE (Sobral, Online). $2019 \mathrm{Jul}$-Dec;18(2):26-33 - 33 